\title{
Measured and Predicted Behaviour of Steel Beams and Columns in Fire
}

\section{Y. ANDERBERG}

Lund Institute of Technology

Lund, Sweden

N. E. FORSÉN

Multiconsult A/S

Oslo, Norway

\section{B. AASEN}

NTH-Sintef

Trondheim, Norway

\section{ABSTRACT}

Analytical predictions of mechanical behaviour of fire-exposed steel structures are compared to experimental results obtained from three different research laboratorjes. Comparisons are made to axially free and restrained steel colums fire tested in Metz in France 1973-74, to simply supported steel beams fire tested in Germany and published in Stahlban 1/1983 and to axially free and restrained steel colums fire tested in Trondheim in Norway 1984.

The measured time-temperature state of the steel structures is used as input information for the analytical prediction of the mechanical behaviour. For the analysts, the structural computer program Steelfire is used. Steelfire is a FEM-program and originates from NTH, Norway. The influence of the degree of axial restraint, load eccentricity and initial deformation in accordance to Dutheils formula are examined. Modelling of mechanical behaviour of steel is also presented.

Predictions and experimental results agree reasonably well, which lllustrate the capability and reliability of the program steelfire.

1. MECHAN ICAL BEHAVIOUR MODEL OF STEEL

It is generally proved that the deformation process of steel at transient high temperatures can be described by three strain components according to the constitutive equation

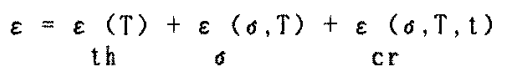

$\varepsilon=\varepsilon(T)+\varepsilon(\delta, T)+\varepsilon(\delta, T, t)$

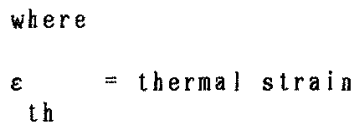

FIRE SAFETY SCIENCE-PROCEEDINGS OF THE FIRST INTERNATIONAL SYMPOSIUM 
$\varepsilon$

o

$\varepsilon$

$\mathrm{cr}$

o

$\mathrm{T}$

$\mathrm{t}$

= instantaneous, stress-related strain based on stress-strain relations, obtained under constant, stabilized temperature

= creep strain or time dependent strain, determined by ordinary creep tests at constant, stabilized stress and temperature

$=$ stress

$=$ temperature

A computer adapted mechanical behaviour model for steel, based on Eq. (1), is developed in Anderberg (1976) 111 and applied in Steelfire I2I.

The strain components are found separately in different steady state tests. It is shown that a behaviour model based on steady state data satisfactorily predicts behaviaur in transient tests under any given fire process, load and strain history.

An analytical description of the $\sigma^{-\varepsilon}$ curve as a function of temperature can be made in different way as illustrated in Figs. 1 and 2 . In the first case the curve is approximated by piecewise linear lines (used in Steelfire 121) and in the second case by an elliptic branch placed between straight lines. In Magnusson (1974) I3I an analytical expression derived by Ramberg and Osgood (1943) 14I was used as follows

$\varepsilon=\sigma / E_{0, T}+3 / 7 * \sigma_{0,2} / E_{0, T} *\left(\sigma / \sigma_{0,2, T}\right)^{*}$

where

$E_{0}, T \quad=$ modulus of elasticity at temperature $T^{\circ} \mathrm{C}$

o. $=$ yield strength or proof strength at room temperature

o. $2, r \quad=y i e l d$ strength or proof strength at temperature To $\mathrm{C}$

m $\quad$ = temperature dependent factor.

For good convergence in computations a smooth curve is to prefer.

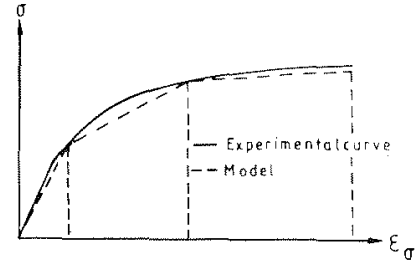

FIGURE 1. Simplified model of the stress-strain curve for steel (used in Steelfire)

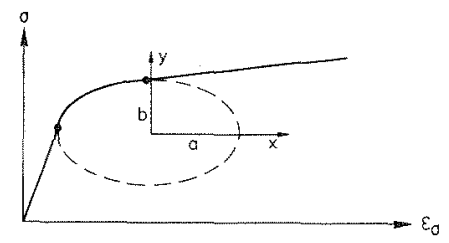

FIGURE 2. Refined model of stressstrain curve for steel 
Models of high temperature creep are in most cases based on the theory put forward by Dorn (1954) 15I, in which the effect of variable temperature is considered by the use of the concept temperature compensated time. The extensian of the model to be applicable to variable stress can, for instance, be based on the strain hardening rule.

\section{STRUCTURAL COMPUTER PROGRAM STEELFIRE}

Steelfire is developed by Forsen (1983) 121 and the program analyses plane steel frames subjected to inplane loading and temperatures varying with time.

The analysis is based on a displacement formulation of the finite element method using straight beam elements. The nonlinear geometric effects (large displacements) are taken into account by updating the nodal coordinates of the structure during deformation. Nonlinear, temperature dependant material properties are considered and the current temperature distribution for each fire zone are recorded step by step from a temperature file.

3. EXPERIMENTAL, INVESTIGATIONS, USED FOR ANALYTICAL SIMULAT IONS

Three different experimental investigations are looked upon as follows.

a) At the Fire Research Station in Metz in France tests were carried out 1973-74 on steel colum of box girder profile (RHS) with different slender nesses $\lambda=40,80$ and 120 with an effective length of $3.84 \mathrm{~m}$ at different degrees of axial restraint, load levels and rates of heating. These tests are analysed and reported by Magnusson (1973) 131. In this paper, only 3 tests are analysed as shown in Table 1.

Table 1 METZ-COLUMNS

\begin{tabular}{lllll}
$\begin{array}{l}\text { Column } \\
\text { test }\end{array}$ & $\begin{array}{l}\text { Initial } \\
\text { Load level } \\
\mathrm{kN}\end{array}$ & $\begin{array}{l}\text { Degree of } \\
\text { axial } \\
\text { restraint } \\
\gamma\end{array}$ & $\begin{array}{l}\text { Load } \\
\text { eccentricity } \\
\mathrm{mm}\end{array}$ & $\begin{array}{l}\text { Collapse } \\
\text { temperature } \\
{ }^{\circ} \mathrm{C}\end{array}$ \\
\hline & & & \\
$M 1-3: 4$ & 460 & 1.0 & 0 & 376 \\
$M 2-5: 4$ & 460 & 1.0 & 7.2 & 319 \\
$M 3-6: 3$ & 230 & 0.8 & 0 & 480 \\
\hline
\end{tabular}

The box-girder columns considered are characterized by steel 1411 with a yield stress $=343 \mathrm{MPa}$, a slenderness ratio $=80$, with $b=127 \mathrm{~mm}$, profile thickness $t=9.5 \mathrm{~mm}$ and by a slow rate of heating $=7^{\circ} \mathrm{C} / \mathrm{min}$. 7 represents the degree of axial restraint where $\gamma=0$ means full restraint and $y=1$ no restraint at all.

Great difficulties to measure deformations were reported and the control of restraint was not perfect. Therefore the experimental results must be taken with care.

b) In Stahlbau 1/1983 I6I Reyer and Nolker present experimental results from beam and column tests carried out in FRG. In this paper a beam test is ana- 
lysed. The beam consists of an IPE 80 profile $\left(\mathrm{h}=80, b=46 t_{1}=\right.$ $=5.2, \mathrm{t}_{\mathrm{w}}=3.8 \mathrm{~mm}$ ) of $\mathrm{St} 37$ with a yield stress of $392 \mathrm{MPa}$. The beam has a lengtb $l=1.14 \mathrm{~m}$ and is loaded by a concentrated load at the midsection. The rate of heating is about $40{ }^{\circ} \mathrm{C} / \mathrm{min}$ i.e. an uninsolated steel beam. This rate of heating gives rise to thermal gradients over the section but the value presented is an average value across the section as well as along the beam. This simplification makes a comparison between test and prediction approximate.

c) A much more comprehensive and well documented experimental investigation is carried out by Aasen (1985) I7l on steel columns. The main calculations are focused on these tests.

The experimental program comprised 15 pinned and 5 axially restrained column tests. All specimens were made of IPE 160 section and had a yield strength $\sigma_{0}=448 \mathrm{MPa}$. A complete description of the test series is given in Aasen 1985 I7I and in this paper only 5 column tests are presented as illustrated in Table 2. The slenderness ratio is 92 and the length of the colums is $1.7 \mathrm{~m}\left(\mathrm{~b}=82, \mathrm{~h}=160, \mathrm{t}_{\mathrm{f}}=7.4, \mathrm{t}_{\mathrm{w}}=5 \mathrm{~mm}\right)$.

\section{Table 2 AASEN-COLUMNS}

\begin{tabular}{lllll}
\hline $\begin{array}{l}\text { Column } \\
\text { test }\end{array}$ & $\begin{array}{l}\text { Initial } \\
\text { load level } \\
\mathrm{kN}\end{array}$ & $\begin{array}{l}\text { Degree of } \\
\text { axial restraint eccentricity } \\
y\end{array}$ & $\begin{array}{l}\text { Load } \\
\text { heating } \\
\text { To C/min }\end{array}$ \\
\hline A1 (16) & 98 & 1.0 & 0 & 7.7 \\
A2 (19) & 98 & 1.0 & 14 & 8.0 \\
A3 (20) & 97.9 & 1.0 & 20 & 8.7 \\
A4 (17) & 98.3 & 0 & 0 & 8.4 \\
A5 (18) & 196 & 0 & 0 & 8.4 \\
\hline
\end{tabular}

The purpose of this study was to perform an experimentally well-defined simulation of the fire behaviour at an exposure according to a typical standard fire test, Fig. 3. The tests were carried out by means of electrical heating equipment using conventional laboratory facilities. As reference, a test specimen from 181 was chosen. The maximum applied load was adjusted according to the recommendations of ECCS, 19I, assuming the original specimen with both ends built in.

The experinental set-up is shown in Fig. 4. The test specimens were mounted in a vertical position and bolted to end fixtures which acted as hinged bearings. The column ends were braced against lateral displacement and torsion. The loading was applied by a $400 \mathrm{kN}$ Ansler hydraulic jack with a load cell located at the top of the colums.

The heating was attained by 6 low voltage elements attached to the outside of the flanges, 3 elements on each side. A typical heating element consisted of a 5.5 m stranded wire runing in loops through ceramic beds. The test specimen was finally insulated with blankets of ceramic fibres which is a material made from synthetic mixes of aluminia and sillca. The power unit provided a $60 \mathrm{~V}$ supply for the heat input, totally $48 \mathrm{~kW}$. 


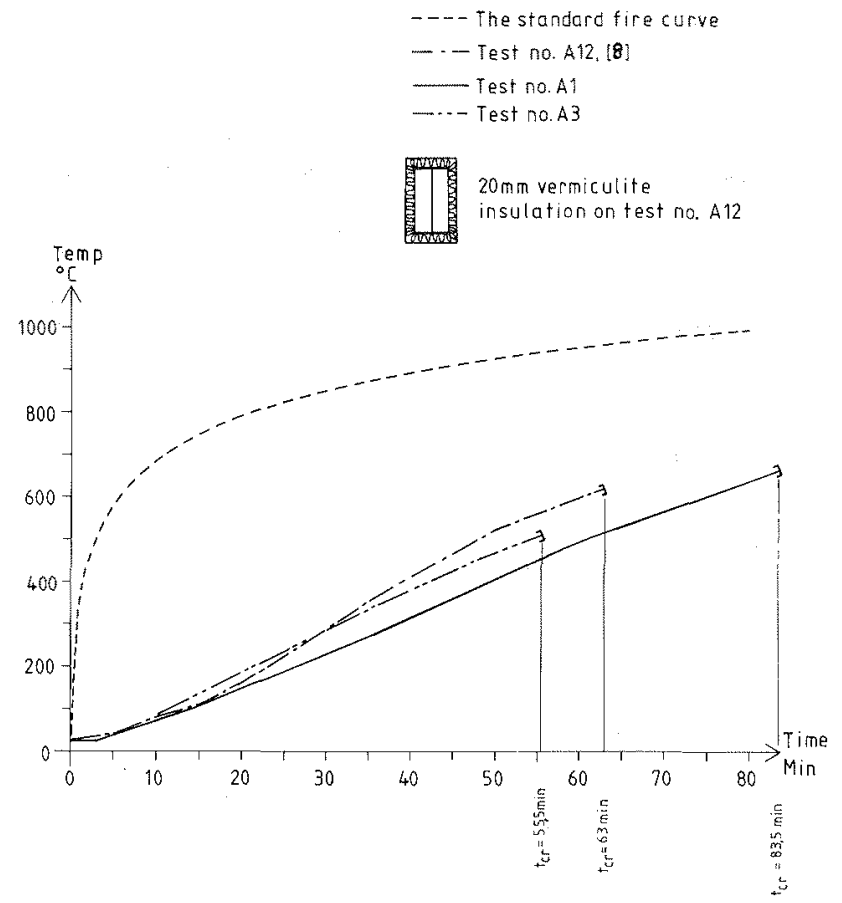

FIGURE 3. Standard fire curve and temperature curve for different tests

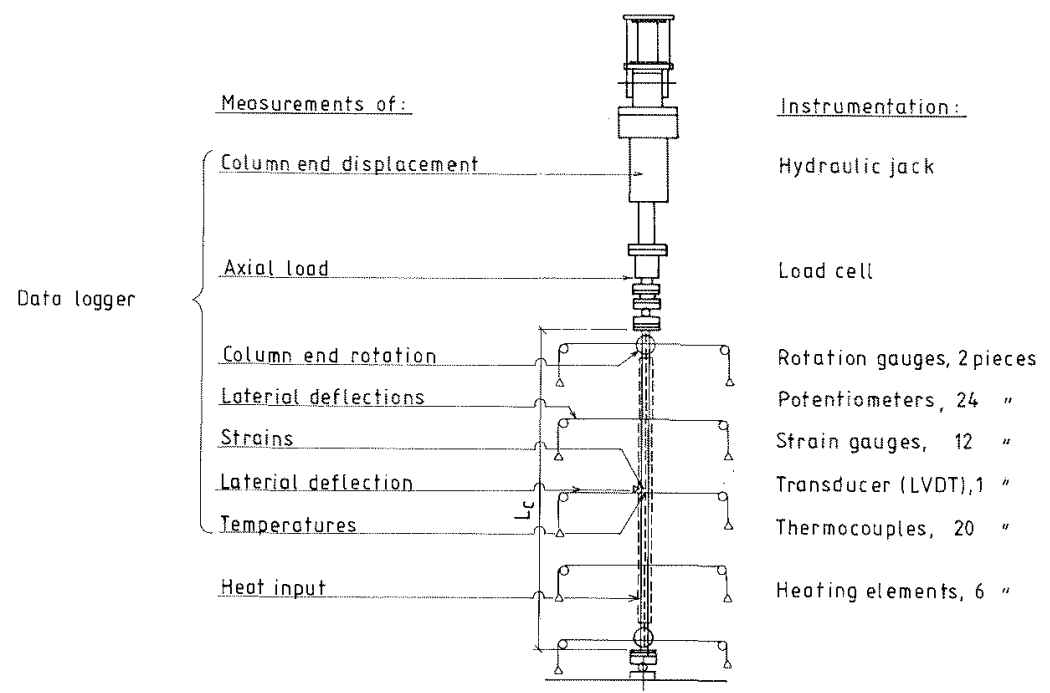

FIGURE 4. Experimental arrangements 
The testing procedure comprised two phases. Firstly, the load was applied in increments at room temperature. Secondly, at a prescribed level the load was kept constant with increasing temperatures. Alternatively, the axial column end displacement was fixed in order to introduce an axial restraint, i.e. $z=$ $=0$.

In general, the failure occurred by in-plane buckling about the weak axis. However, flexural-torsional buckling was observed when conducting tests with restraining beams. Due to a modification of the bracings a the end fixtures, the test rig became sensitive to torsion.

The temperature measurements showed appoximately uniform temperatures along the central part of the specimens with steep gradients at the ends. Regarding columns Nos. 1-5, negligible cross-sectional temperature gradients were recorded.

In canclusion, the test procedure described in this paper allows representathe steel columins to be tested under controlled conditions of high temperatures. Thus, it is possible to investigate the behaviour of fire exposed steel members in a simple way.

\section{COMPARISON BETWEEN MEASURED AND PREDICTED BEHAVIOUR}

The structural response is predicted by use of Steelfire for the structural members described in previous chapter. The temperature input for Steelfire is taken direct from measirements as an average value varying with time and representative for the whole structure. When the test is performed in a furnace with gas- or oilburners (tests in Metz and FRG), this simplification is very rough. When the healing is simulated by electrical elements this approximation is more adequate.

\subsection{Beams}

The structural response of a simply supported, fire-exposed steel beam (IPE) 80) is illustrated in Fig 5 by deflection curves. The test conditions and the

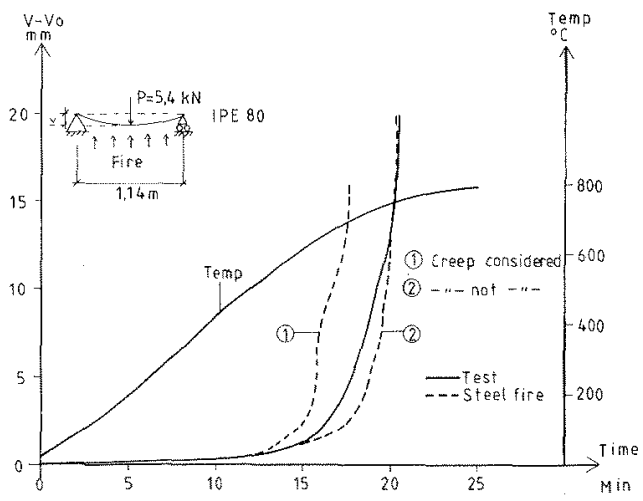

FIGURE 5. Measured and predicted deflection of firemexposed simply supported beam tested in FRG 161 . The influence of creep is also shown 
average temperature as function of time is alsogiven in the figure. The predicted deflection process is shown for the cases with and without creep and its importance is obuious. The predicted deflection curve is in satisfactorily agreement with the measured curve where the failure time is 17.5 and 20.5 min respectively. If creep is neglected, the agreement happens coincidentally to be better than if creep is considered. Temperature approximations and the incomplete documentation of the test make results somewhat uncertain.

\subsection{Colums}

\subsubsection{Simply supported}

The deflection behaviour of Metz-colums M1 and M2 is illustrated in Fig 6.

The load is $460 \mathrm{kN}$ but only M2 is eccentrically loaded ( $=7.2 \mathrm{~mm}$ ) and the average temperature is shown. Even if measured deflection is somewhat uncertain the predictions are quite close but fallure time is attained about 8 min earlier in the tests. One important reason for that is the initial deformation of the steel column which in accordance with Dutheils formula is $f=4.8 * 10^{-5}$

$L_{f} 2 / d=11 \mathrm{~mm}$. Unintentional load eccentricity may also influence. From Fig 6 it can be seen that the test M1 coincides with the prediction of M2 representing a load eccentricity of $7.2 \mathrm{~mm}$ which is less than $\mathrm{f}$ !

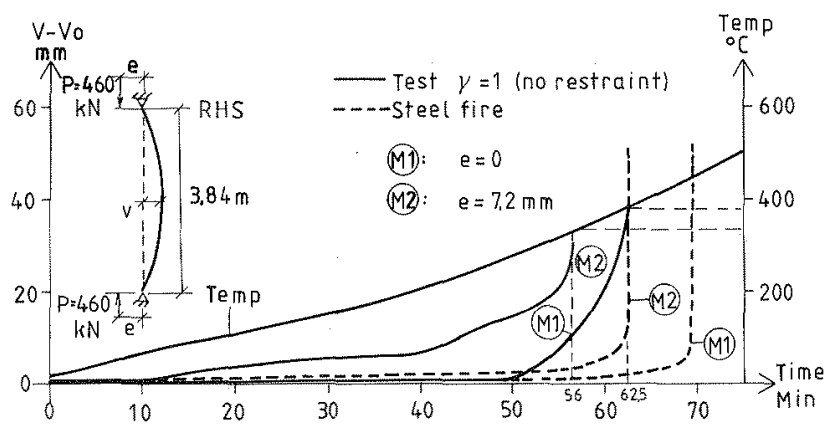

FIGURE 6. Measured and predicted deflection of fromall sides fire-exposed steel colums tested in Metz I3I. The influence of eccentricity is also shown

The prediction of the Aasen tests $A 1, A 2$ and $A 3$ with the load eccenticities 0 , 14 and $20 \mathrm{~mm}$ respectively are shown in Fig 7 . The load level is $98 \mathrm{kN}$ and the initial deformation as calculated above is only $2 \mathrm{~mm}$. The temperature curve for every individual test is given. The agreement between predicted and measured curves is very good and the initial deformations and unintensional load eccentricity can easily explain the differencies.

The concordance is very much due to well performed tests under controlled conditions. 


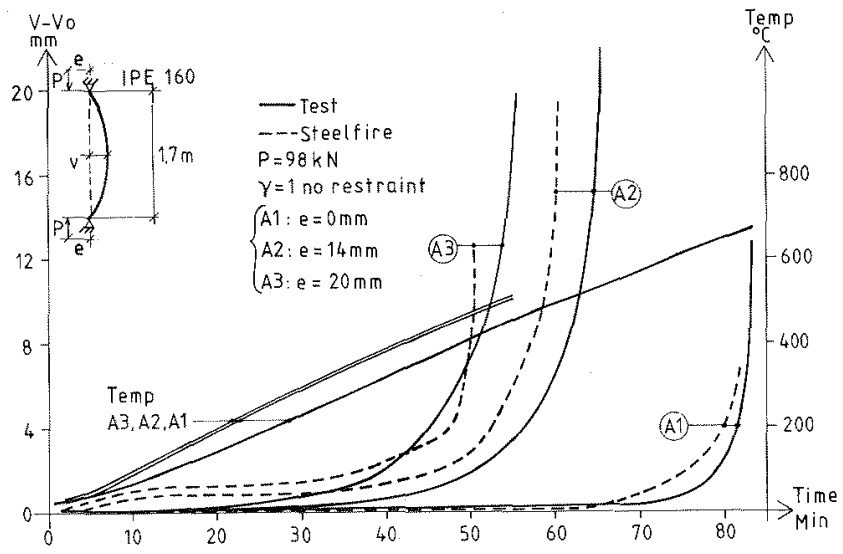

FIGURE 7. Measured and predicted deflection of from all sides fire-exposed steel colums tested in Norway I7I. The influence of eccentricity is also shown

\subsubsection{Axially restrained}

Full restraint is very difficult to accomplish in practise and it is also very hard to simulate and control experimentally a specific degree of restraint as experienced in the Metz-tests. Two predictions are illustrated in Fig 8 for the case full restraint $y=0$ at the initial load $=460 \mathrm{kN}$ and for the case $\gamma=0.8$ at the iaitial load $=230 \mathrm{kN}$. In the prediction of M3 the measured variation of axial force was followed in the calculation of deflection.

In the simulated case of full restraint the maximum restraint force attained about $900 \mathrm{kN}$ after already $10 \mathrm{~min}$ and then it diminished and passed the in tial force after $30 \mathrm{~min}$ which corresponds to fallure time if minimum load is $460 \mathrm{kN}$. This rapid increase followed by a sudden decrease in axial load is very typical for axially restrained colums.

Deflection measurements are not made for the test M3 but fallure temperature is $480^{\circ} \mathrm{C}$ compared to predicted $375^{\circ} \mathrm{C}$. Experimental difficulties may have influenced the result. When the measured variation of the axial restraint force is followed in the calculation it is noticed that the prediction of the deflection process may differ very much from the measured curve. This is due to the very high sinsitivity to the restraint condition and the sudden decrease in restraint force but also due to the discrepancy between "real" and assumed mechanical and geometrical properties as well as the temperature distribution of the steel member.

The reliability of the colum tests carried out by Aasen are comparatively good but one problem has arisen namely to obtain a complete restraint. The tests A4 and A5 with the load levels 98 and $196 \mathrm{kN}$ at approximately full restraint have principally the same behaviour as the fully restrained Metz-column discussed above. The initial deformation is calculated to $f=2 \mathrm{~mm}$.

The predicted behaviour of the test A4 (assumed eccentricity $e=1$ mo) can be followed in Fig 9 where the axial force increases rapidly and attain a maximum value of $380 \mathrm{kN}$ after $10 \mathrm{~min}$. The test value is $345 \mathrm{kN}$ attained after $22 \mathrm{~min}$ 
a)

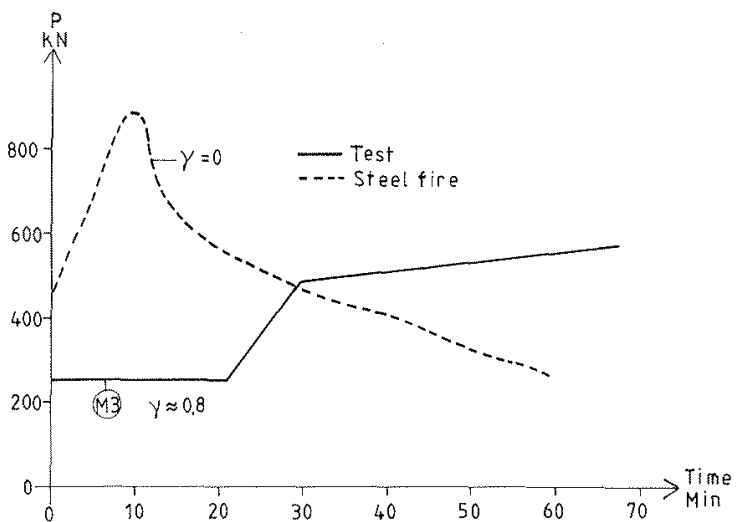

b)

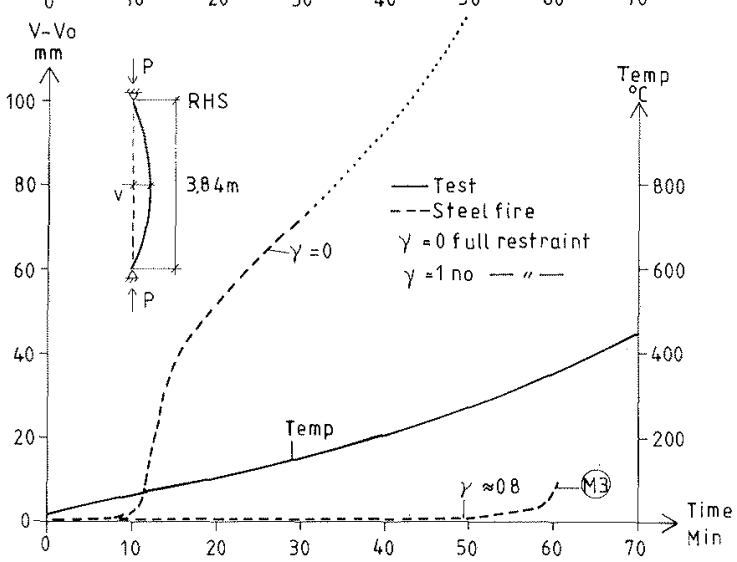

FICURE 8. Measured and predicted behaviour of from all sides fire-exposed and axially restrained steel columns tested in Metz in France I3I
a) Axial restraint force
b) Deflection

but the discrepancy is due to inevitable movements in the loading arrangements at the supports. Therefore a prediction is made where the colum was free to move axially $1 \mathrm{~mm}$ before full restraint was applied and the behaviour was very much influenced. The development of axial force started after 16 min and met the measured maximum value and followed after that the measured curve. Deflection curves came also very close to each other. If however a spring of approm priate stiffness (representative for load arrangement) was applied at the supports until $\Delta$ attained $1 \mathrm{~mm}$ also the first part of the curve of axial force would be close. The observed phenomena illustrates the sensitivity of the degree of full restraint on the axial force.

The influence of increasing the eccentricity to $2 \mathrm{~mm}$ (compare to $\mathrm{f}=2 \mathrm{~mm}$ ) is also shown but will only influence the level of axial restraint force.

The result of the test A5 is given in Fig 9 but not predicted. In this test the higher initial load level (196 kN) results in a higher maximum load $420 \mathrm{kN}$ occuring already after $18 \mathrm{~min}$. 
a)

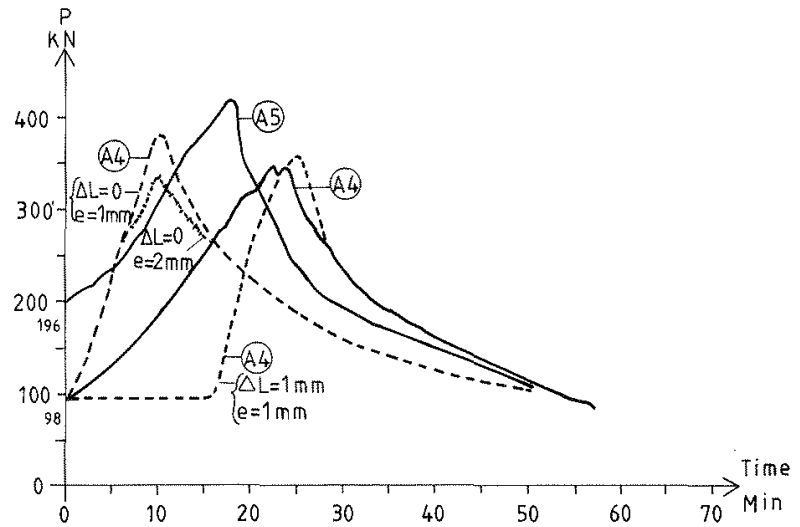

b)

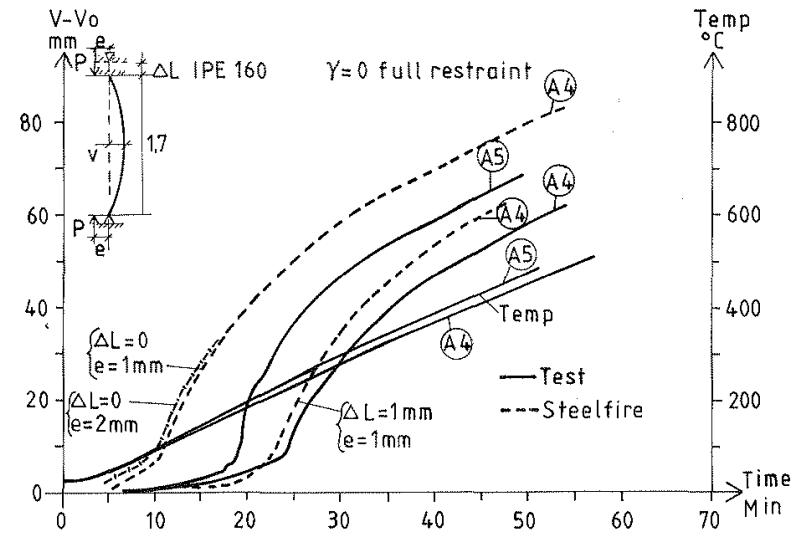

FIGURE 9. Measured and predicted behaviour of from all sides fire-exposed and axially restrained steel columns tested in Norway I7 I
a) Axial restraint force
b) Deflection

5. HOW TO REDUCE THE DISCREPANCY BETWEEN MEASURED AND PREDICTED STRUCTURAL BEHAVIOUR

A detailed documentation of tests performed under thoroughly controlled conditions with an equipment of high reliability is a desirable situation for predicting structural response with good agreement to measurements.

In order to obtain this good concordance the theoretical modelling of the mechanical behaviour of the materials involved, the capability and reliability of the structural program is of decisive importance.

The equipment used for testing fire-exposed structures with complicated support conditions have been improved all the time and in this paper the importance of successful tests for good agreement is demonstrated.

It must be emphasized that a complete end restraint is almost impossible to obtain but this situation will never exist in practise either. 
Electrical heating on steel structures ives the best control of temperature state with very small gradients along and across the member as a result I7I.

Improvements in modelling can also be made. The -e curve ought to be a smooth curve instead of a piecewise linear relationship to improve convergence. Creep parameters are tabled for different kind of steels but there can be a considerable difference between tabled and 'real' values. There is a need for more data on creep properties.

\section{CONCLUSIONS}

* Steelfire has a good ability to describe real behaviour at fire.

* Test conditions are difficult to define beyond all doubts, especially at a high degree of restraint against axial deformation.

* Steelfire can be used to derive and describe real test conditions of experiments and thereby facilitate analysis and generalization of test data. However, the modelling is still a simplification or approximation of the real situation. It is always a coincidence if the predicted curve exactly follows the measured curve.

\section{REFERENCES}

1. Anderberg, Y. : Fire-Exposed Hyperstatic Concrete Structures - An Experimental and Theoretical Study. Division of Structural Mechanics and Concrete Construction, Lund Institute of Technology. Bulletin 55, 1976. Lund.

2. Forsén, N.E. : Steelfire-Finite Element Progran for Nonlinear Analysis of Steel Frames Exposed to Fire Users Manual. Multiconsult A/S, Oslo. 1983.

3. Magnusson, S.E. : Stálpelares Verkningssätt och Bärförmága vid Brand. Säkerhetsprablemet vid Brandpaverkade Stälkonstruktioner. (Structural Behaviour and Loadbearing Capacity of Fire-exposed Steel Colums. Safety Problem of Fire-exposed Steel Structures). Division of Building Fire Safety and Technology. Lund Institute of Technology, Lund 1974. (In Swedish).

4. Ramberg, W. and Osgood, W. : Description of Stress-Strain Curves by Three Parameters. NACA Technical Note No 902, 1943.

5. Dorn J.E. : Some Fundamental Experiments on High Temperature Creep. Journal of Mechanics and Physics of Solids 3 (1954) 35, London.

6, Reyer, E \& Nölker, A.: Zum Brandverhalten von Gesamtkonstruktionen des Stahl- und Stahlverbundbaues. 1 Teil: Verfahren, Eignungstests und Vergleichberechnungen zur experimenteller Untersuchung mit Grossmodellen (Fire behaviour of steel structures). Der Stahlbau 1/1983.

7. Aasen, B. : Buckling of Steel Columns at Elevated Temperatures. Dr. Ing Thesis, NTH, Trondheim 1985 (in preparation).

8. Knublauch et al : Berechnug der Stahltemperatur von Stahlstiitzen. (Calculation of Temperature for Steel Colums). Der Stablbau 6 and $8,1974$.

9. ECCS : European Recommendations for the Fire Safety of Steel Structures. Elsevier SC. Pub. Co, Amsterdam - Oxford - New York, 1983. 
G 